\title{
Bang for Your Buck: Rejection Rates and Impact Factors in Ecological Journals
}

\author{
L.W. Aarssen ${ }^{1, *}$, T. Tregenza ${ }^{2}$, A.E. Budden ${ }^{3}$, C.J. Lortie ${ }^{4}$, J. Koricheva ${ }^{5}$ and R. Leimu ${ }^{6}$
}

\begin{abstract}
${ }^{1}$ Department of Biology, Queen's University, Kingston, ON, K7L 3N6, Canada $;{ }^{2}$ Centre for Ecology and Conservation, University of Exeter, Cornwall Campus, Tremough, Penryn, TR10 9EZ, UK $;{ }^{3}$ Department of Biology, York University, 4700 Keele St., Toronto, Ontario, M6S 2E2, Canada; ${ }^{4}$ National Center for Ecological Analysis and Synthesis, 735 State Street, Suite 300. Santa Barbara, CA 93101; ${ }^{5}$ School of Biological Sciences, Royal Holloway, University of London, Egham, Surrey, TW20 OEX, UK; ${ }^{6}$ Department of Biology, University of Turku, FIN-20014, Finland
\end{abstract}

\begin{abstract}
When choosing where to submit their research for publication, most ecologists are concerned with journal impact factor, but they are also concerned with the likelihood that their manuscripts will be accepted. Based on a survey of ecologists, we found different degrees of relative concern for these journal attributes depending on author experience and gender. However, the ability of authors to choose among journals based on these journal attributes is limited: while journal impact factors are published regularly, journal rejection rates are not. We obtained, by permission, rejection rate data for a sample of 60 ecology journals for the year 2004. As expected, journals with higher impact factors also have higher rejection rates, but the ratio of [rejection rate] / [impact factor] increases sharply with decreasing impact factor below 1.76. Journals with impact factors below this value therefore provide relatively low payback in terms of impact against cost as estimated by rejection rate. We discuss alternative possible interpretations of this relationship and alternative criteria that might affect an author's decision about journal choice. Most importantly, our analysis indicates that the ability to make informed choices requires that journals publish their rejection rates annually.
\end{abstract}

\section{PREAMBLE}

How does an author decide where to submit a paper for publication? This important decision is made routinely throughout the career of a typical researching scientist/academic. The choices made can profoundly affect the trajectory, rate of progress, and status of one's research career. Necessarily, the subject category of the journals under consideration must be concordant with the research topic of the paper. However after this, most authors in the field of ecology at least, are usually still presented with more than one choice of a topically suitable subset of candidate journals. And, when the paper is rejected (an experience that few if any manage to avoid completely), the author is commonly inclined to iteratively select alternative journals.
With each iteration, the author selects a journal on the basis of several distinguishing traits including journal impact factor, likelihood of acceptance, and likelihood of rapid decision. The relative importance and scope of application of impact factors and other publication related metrics is not without debate, i.e. how broadly they apply between researchers, fields, and journals, and how accurately they describe the relative success of a journal or publication scientifically [1-4]. Nevertheless, in our recent survey of ecologists, the majority of 1250 respondents rated all three journal traits, including impact factor, as either 'important' or 'very important' (Table 1), although less so with respect to likelihood of acceptance. Of course, from an author's perspective, the 'ideal' journal would have a high impact factor, a high likelihood of acceptance, and provide a rapid decision. In this study, we test whether journals with the first two desirable attributes exist. More

Table 1. Percentages of Survey Responses $(\mathrm{N}=1250)$ in which Participants were Asked to Rate the Importance of Three Factors when Selecting a Journal for Submitting Manuscripts. [The Web-Based Survey was Designed by the National Centre for Ecological Analysis and Synthesis (NCEAS) Ecobias Working Group (www.ecobias.org), and was Posted Online from May $4^{\text {th }}, 2006$ to November $4^{\text {th }}, 2006$ ]

\begin{tabular}{|c|c|c|c|c|}
\hline Factor & Very Important & Important & Somewhat Important & Not Important \\
\hline \hline High journal impact factor & 39.6 & 46.0 & 12.6 & 1.8 \\
\hline High likelihood of acceptance & 11.2 & 44.3 & 36.7 & 7.8 \\
\hline High likelihood of rapid decision & 25.2 & 47.0 & 22.5 & 5.3 \\
\hline
\end{tabular}

*Address correspondence to this author at the Department of Biology, Queen's University, Kingston, ON, K7L 3N6, Canada; E-mail: aarssenl@queensu.ca specifically, we identify the realized phenotype, or set of traits, for the majority of ecological journals including number of papers received or published, gender of authors, citation rates over time, and total number of authors. We also integrate these 
findings with the submission preferences expressed by gender in the survey data and also provide a general metric of payback for cost (rejection) relative to gain (impact factor).

\section{ANALYSES AND RESULTS}

The sample pool of ecological journals (107) was defined as the inclusive list of journals listed in the 'Ecology' category by ISI Science (www.isiwebofknowledge. com). Rejection rates were assigned by contacting the editors independently for all 107 journals. Editors were asked to provide the rejection rate for their journal for 2004. The response rate was $56 \%$ ( $N=60$ journals) (Table 2). Impact factor was obtained from ISI Web of Science.
The mean IF for responding journals (1.69) did not differ significantly from that of non-responding journals (1.86) (ttest; $\mathrm{P}=0.617$ ).

The likelihood of rejection increases with increasing journal impact factor (Fig. 1, Pearson's product moment correlation: $r=0.741, P<0.001$; partial correlation with number of papers published in 2004 held constant: $r=0.687$, $P<0.001)$. This is not surprising, however the relationship is more accurately described as 'triangular' with a linear 'lowerbound' to the distribution (dashed line in Fig. 1). In other words, there is an absence of high impact factor journals with a low rejection rate (the bottom right corner), but there are many journals with a low impact factor and relatively high rejection rates (top left corner of the graph).

Table 2. The 60 Journals from the 'Ecology' Category List Provided by ISI Web of Science (http://www.isiwebofknowledge.com/) that Responded to Our Request for Rejection Rate Data

\begin{tabular}{|c|c|}
\hline American Naturalist & Journal of Evolutionary Biology \\
\hline Animal Conservation & $\mathrm{J}$ of Experimental Marine Biol and Ecol \\
\hline Annales Zoologici Fennici & $\mathrm{J}$ of the NA Benthological Society \\
\hline Applied Vegetation Science & Journal of soil water conservation \\
\hline Aquatic Microbital Ecology & Journal of Vegetation Science \\
\hline Austral Ecology & Journal of Wildlife Management \\
\hline Basic and Applied Ecology & Landscape Ecology \\
\hline Behavioural Ecology & Microbial Ecology \\
\hline Biotropica & Natural Areas Journal \\
\hline Chemoecology & New Zealand Journal of Ecology \\
\hline Conservation Biology & Northeastern Naturalist \\
\hline Ecography & Oikos \\
\hline Ecological Economics & Oryx \\
\hline Ecological Engineering & Proceedings of the Linnean Society of NSW \\
\hline Ecology Letters & Paleobiology \\
\hline Ecological Research & Pedobiologia \\
\hline Ecoscience & Plant Ecology \\
\hline Ecosystems & Polish Journal of Ecology \\
\hline Ecotoxicology & Polar Biology \\
\hline Evolutionary Ecology & Population Ecology \\
\hline Evolutionary Ecology Research & Rangeland Journal \\
\hline Evolution & Restoration Ecology \\
\hline Functional Ecology & South African Journal of Wildlife Research \\
\hline Global Ecology and Biogeography & Southeastern Naturalist \\
\hline Journal of Animal Ecology & Southwestern Naturalist \\
\hline Journal of Applied Ecology & Western North American Naturalist \\
\hline Journal of Arid Environments & Wetlands \\
\hline Journal of Biogeography & Wildlife Biology \\
\hline Journal of Chemical Ecology & Wildlife Monographs \\
\hline Journal of Ecology & Wildlife Society Bulletin \\
\hline
\end{tabular}




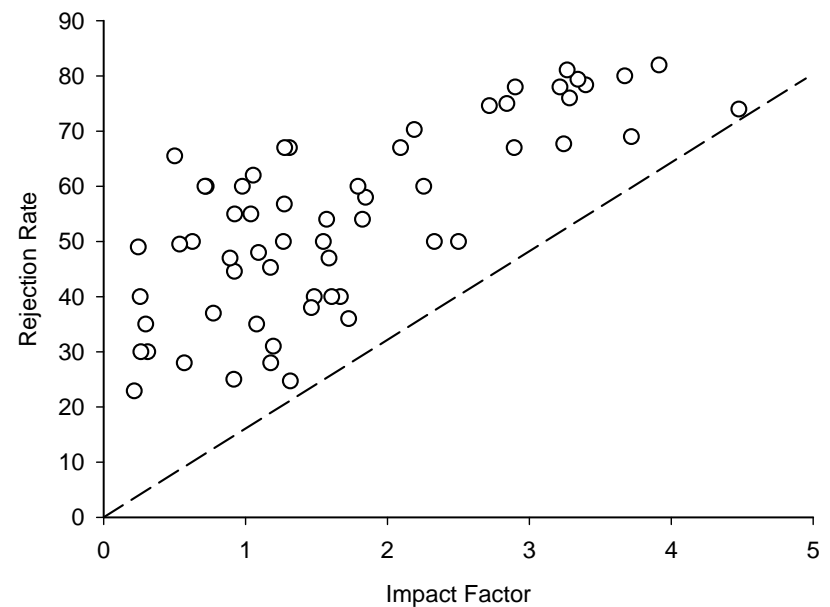

Fig. (1). Scatterplot showing the relationship between journal impact factor in 2004 and the percentage of papers rejected in 2004 for 60 journals listed in the 'Ecology' category by ISI Web of Science (http://www.isiwebofknowledge.com/). The relationship is significantly positive (partial correlation with number of papers published in 2004 held constant: $r=0.687, P<0.001$ ), but note the generally triangular data distribution with a 'lowerboundedness' indicated by the dashed line through the origin.

Authors wishing to be strategic in their publishing behaviour might selectively favour journals with a low rejection rate to impact factor (RR/IF) ratio for submission of their articles. In our dataset, the median RR/IF ratio was 32.1 (range $16.5-200.8$ ). Therefore, journals with a ratio above this value may represent a more 'risky' strategy given a relatively low payoff, and it is unfortunate that rejection rate information is not readily available to authors.

There was an inverse relationship between journal impact factor and the RR/IF ratio (Fig. 2, $\mathrm{F}_{1,58}=241.94$, $\mathrm{p}<$ $\left.0.001, r^{2}=0.81\right)$ with higher impact factor journals demonstrating a lower (more favourable) ratio. There was no tendency for either applied journals or fundamental journals to have relatively low ratios. The point at which the inverse regression intercepts the median ratio value of 32.1 is where the journal impact factor is 1.76 . Hence in the absence of information on rejection rate, authors wishing to balance publication in a high impact factor journal against rejection rate should target journals with an impact factor above this value. Of course this value may change annually with changing impact factors and rejection rates, thus recommending that journals publish both metrics on a regular basis. This finding is entirely surprising in that the assumption most commonly adopted in ecology is that to submit to a lower impact journal comes at a limited to no cost in terms of rejection, i.e. net payback likely exceeds cost of rejection. This is not necessarily the case based upon the analysis of cost versus benefit proposed here. Admittedly, some lower impact journals do have favourable ratios $(<32.1)$. However, below an impact factor of 0.9 , all journals' ratios exceed

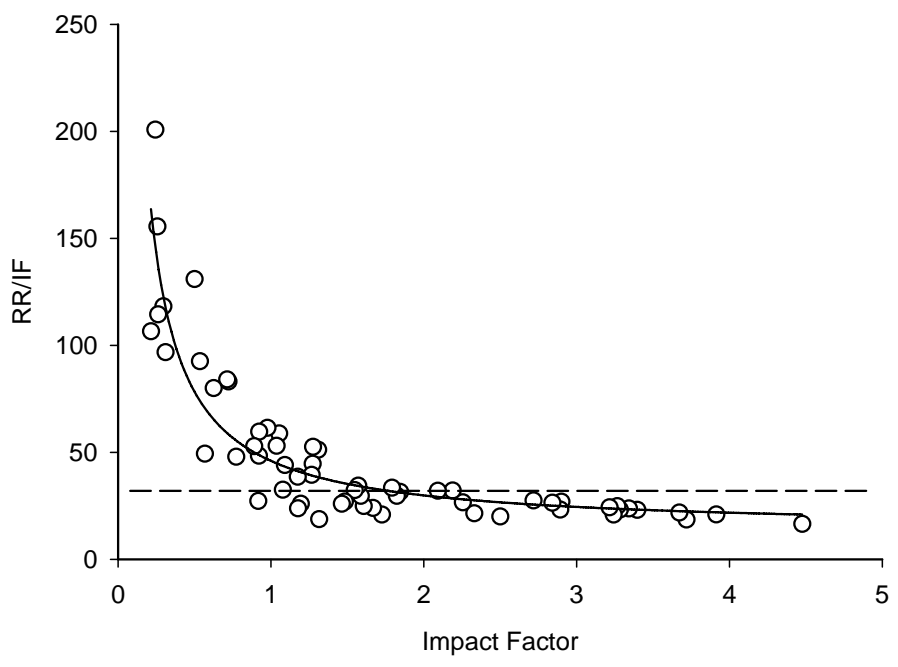

Fig. (2). Relationship between journal impact factor and the ratio of rejection rate to impact factor. Solid line represents a significant inverse relationship and dashed line reflects the median ratio of 32.1.

the median value which suggests that there is little to recommend these journals for an author that is deciding where to submit.

This trade-off between impact factor and the likelihood of manuscript acceptance presents an interesting dilemma given the results from our on-line survey indicating that most authors rank both of these journal traits as important or very important in deciding where to submit. Moreover, the relative importance placed on journal impact factor versus acceptance probability depends on whether an author had previously published in top-ranking, high impact factor journals. Impact factor was more important to the authors that had previously published in these journals $\left(\chi_{3}^{2}=30.99, \mathrm{p}<0.001\right)$, whereas acceptance probability was more important for those authors that had not $\left(\left(\chi_{3}^{2}=17.86, p<0.001\right)\right.$ (Fig. 3). (There was no difference with respect to decision time, Fig. 3). In addition, females were significantly more concerned about a journal's acceptance probability than were males $\left(\chi^{2}{ }_{3}=11.23, \mathrm{p}=\right.$ $0.011)$, whereas males were more concerned about rapid decision time $\left(\chi_{3}^{2}=9.81, \mathrm{p}=0.020\right)$ (Fig. 3). (There were no gender differences with respect to the importance of impact factor $\left(\chi_{3}^{2}=2.46, p=0.482\right.$; Fig. 3).

Differences in the reported submission strategies by gender or career stage in the survey data has important implications on publication bias. Consider for example, the author who is ready to submit a new and very high quality manuscript, i.e. with high 'relative actual merit', or RAM [5], but the author chooses to submit the paper to a journal with a relatively modest rejection rate - e.g. because the author, working in a competitive field or with a novel idea, may be anxious to get the paper published quickly. One way to do this is to avoid the potential delay associated with starting at the top and submitting repeatedly to a list of journals with progressively lower impact factors. Hence, the author gets the paper published relatively quickly because the paper required only one submission - to a journal with a relatively modest rejection rate. However, because the journal also has a relatively modest impact factor (Fig. 1), this is used directly by colleagues as an indicator of only modest 'relative perceived 

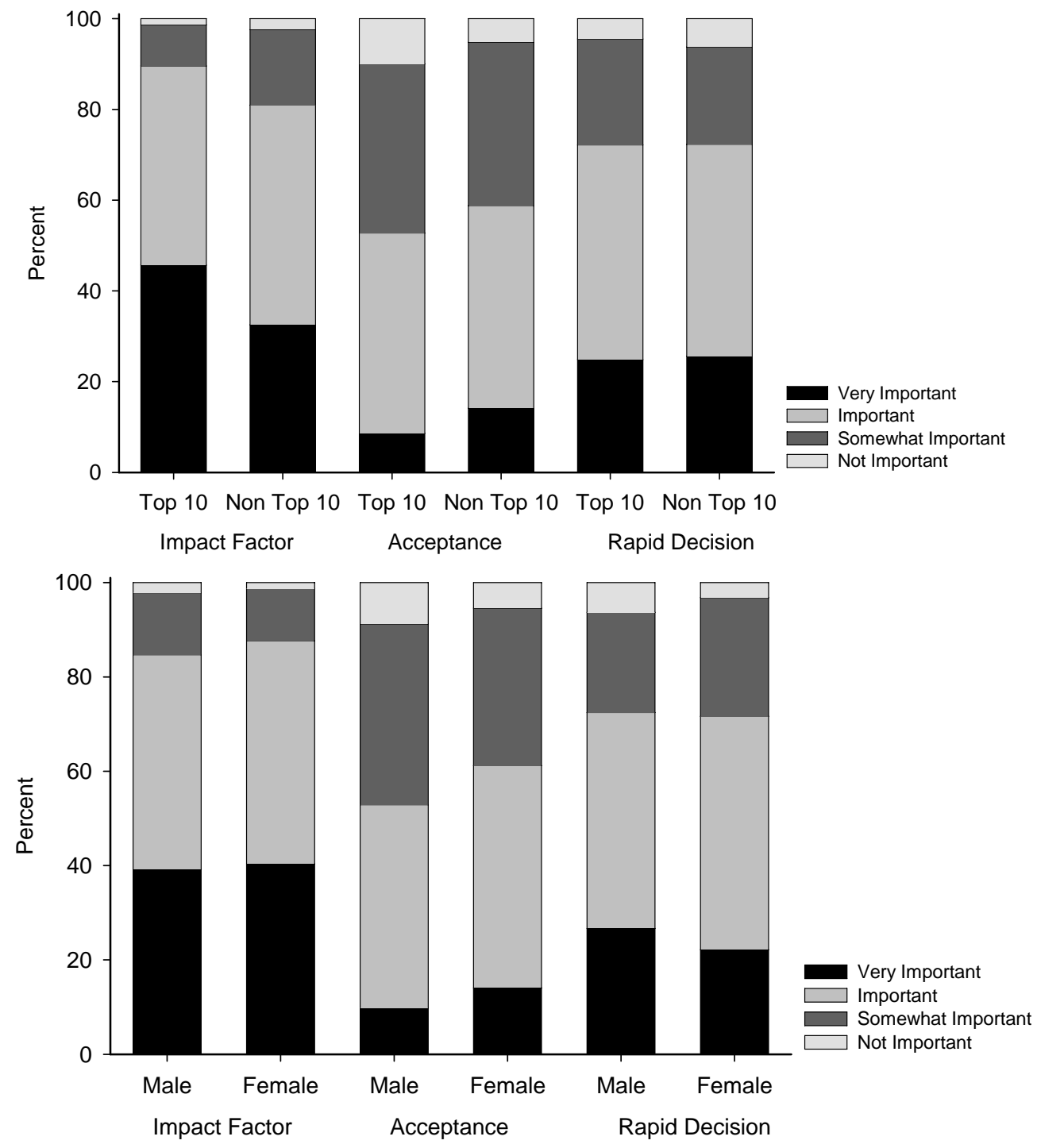

Fig. (3). Percentages of survey responses $(\mathrm{N}=1263)$ in which participants were asked to rate the importance of three factors when selecting a journal for submitting manuscripts: journal impact factor, likelihood of acceptance, and likelihood of rapid decision. In the top panel respondents were grouped according to whether they had published previously in one or more of ten top-ranking, high- impact-factor journals (Nature, Science, PNAS, PLoS Biology, Current Biology, Ecological Monographs, American Naturalist, Ecology, Ecology Letters, Evolution) ("Top 10), or not ("Non Top 10"). In the bottom panel, respondents were grouped by gender. [The web-based survey was designed by the National Centre for Ecological Analysis and Synthesis (NCEAS) Ecobias working group (www.ecobias.org), and was posted online from May $4^{\text {th }}, 2006$ to November $\left.4^{\text {th }}, 2006\right]$.

merit' (RPM) [5]. This disadvantage for the author comes into effect immediately upon publication and is guaranteed to last for at least a few years because it takes this long for the paper to attain any noticeable citation rate that might accrue because of its own RAM, rather than the RPM that is attached to it simply because of the journal name that it is published in.

\section{Consideration of Other Journal Phenotypic Traits}

The number of papers published in 2004 for the journals analyzed here was also positively correlated with impact factor (partial correlation, $r=0.316, P=<0.05$ )) but not with rejection rate (partial correlation, $r=0.048$, $P>0.05)$. These trends suggest at least three potential causative relationships. First, number of papers published may be a driver of impact. Journals that publish more papers may have a higher statistical probability, simply because of their sheer numbers, of publishing the best of the best papers (a kind of 'sampling effect'). This will have little or no effect on their mean impact factor [see Yasui [6] for treatment of an analogous situation in biology] because impact is calculated as a ratio of citations to articles published. Nevertheless, if exceptionally high quality (EHQ), but rare, papers are the main drivers of a journal's impact factor [7], the journals with highest impact factors should generally be the small ones that got 'lucky'. Medium impact factor journals will be large ones that always get their fare share of EHQ submissions, and poor impact factor journals should be the small ones that didn't get lucky that year. This allows us to make a clear prediction: if there is a significant sampling effect, we would expect to find greater between-year variance in impact factor for those journals that publish relatively few papers per year. This pattern has been previously reported for a 
sample of 4000 journals [8]. Analysis of the 85 journals listed as ecology where data are available for all years 2000-2005 fails to replicate this result: a Spearman correlation of mean number of papers published by each journal over the 6 years with the standard deviation in impact factor finds no relationship between the two $(\mathrm{R}=$ $0.05 \mathrm{P}=0.97)$. There is a positive correlation between mean journal size and impact factor over these 6 years $(R=$ $0.34 \mathrm{P}=0.001)$.

Second, impact factor itself may be a driver of rejection rate. Compared with lower impact factor journals, higher impact factor journals may attract more submissions and so these journals generally respond to (or cope with) this higher volume in one of two ways: (a) publish more of them (in terms of absolute numbers published), and (b) reject a higher percentage of the submissions. Mostly, however they do (b), as suggested by the fact that the strongest correlation is between impact factor and rejection rate.

Thirdly, rejection rate may be the driver of impact. Under this scenario, higher rejection rate alone directly elevates the impact factor of the journal by filtering out inferior manuscripts and only publishing the best. This effect could also be further promoted by perception of journal quality by the community in that if a journal is harder to publish in, it must be a better journal (although as shown above, this perception can be wrong).

To contrast the causal explanations, we used longitudinal (between-year) rejection rate data that were provided by 16 journals. We calculated correlation coefficients between rejection rate and the number of citations those articles received in the following year and between rejection rate and the number of papers published for each journal separately. We then used these values to calculate a common correlation coefficient and a $t$ value for significance testing [9]. We detected a significant positive correlation between rejection rate and number of citations in the next year $(\mathrm{R}=0.27, t=2.51$. d.f. $=79, \mathrm{P}=$ $0.014)$ which supports the latter explanation that rejecting more papers increases quality. However, there was also a significant positive correlation between rejection rate and the number of papers published $(\mathrm{R}=0.26, t=2.35$, d.f. $=$ $79, \mathrm{P}=0.021)$ which also supports the explanation that higher rejection rates are a response to higher numbers of manuscripts submitted. Hence, high rejection rate does provide a means to publish higher impact papers but the 'decision' to reject at a high rate is likely a response by editors to high submission volume.

Other attributes of a journal might include the proportion of papers that are female first-authored, the mean number of authors that are published within a given journal, or sensitivity of the performance of the journal to other measures in addition to impact factor. Here, the proportion of the female first authors did not relate to rejection rate (Regression analysis, $\mathrm{r}^{2}=0.001, \mathrm{p}=0.77$ ) which suggests that gender of published papers does not predict rejection rate. However, this is the pool of already published papers and there were significantly more male first-authored papers (ANOVA, $\mathrm{F}=414, \mathrm{p}=0.0001$; mean proportion male $=0.78+/-0.01)$. Hence, it would be invaluable to compare the distribution of papers submitted to journals by impact factor. The mean number of authors per paper published within a journal also did not relate to the rejection rate (Regression analysis, $\mathrm{r}^{2}=0.02, \mathrm{p}=0.26$ ) and only very weakly to impact factor (Regression analysis, $\mathrm{r}^{2}=$ $0.07, \mathrm{p}=0.04$ ) which differed from previous studies showing that articles with more authors generally accrue greater citations [10]. Finally, the h-index for journals for a specific year can be used to compare journal performance [11]. This index was tested as an alternative to impact factor with the 60 journals reporting rejection rates and there was a positive, triangular-bounded distribution similar to the impact factor pattern. Hence, a ranked list of the most highly cited papers within each journal (h-index) also supports the conclusion that in some journals very highly cited papers correspond to a high rejection rate but that in other journals with few highly cited papers rejection rate can still be very high.

\section{Recommendations and Solutions}

Not all journals are created equal. Some journals provide relatively low payback in terms of impact against cost as estimated by rejection rate. This is a novel finding. If authors are concerned with impact, then these individuals should not submit to journals with an impact factor less than 1.76. However, a journal that has a low impact factor may also have a high rejection rate (toward the top left corner in Fig. 1) simply because it has a high submission rate of low quality papers. Since the probability of rejection is also a function of the quality of one's paper, then a high quality paper submitted to a journal with a high $\mathrm{RR} / \mathrm{IF}$ ratio should have a higher likelihood of acceptance than predicted on the basis of the journal's rejection rate.

Differences in submission strategy by gender or career stage can promote bias in that perceived rejection rate of a journal is assumed lower for lower impact journals and the decision to submit to these journals is not equal between different groups of scientists. This inaccurate assessment means that those less aggressive or confident pay a greater cost. Hence, journals should report rejection rate annually. The gain associated with increased rejection rate is not driven by a sampling effect and does to a certain extent reflect quality of papers published. However, we strongly encourage editors to carefully consider and track rejection rates (including author demographics if possible) as increasing the rate of rejection due to increased submission volume is not the only solution to saturation within a discipline of potential publications. Finally, we would be remiss without reminding readers that impact factor is but one criterion to judge the success of a publication, and that authors and editors alike should consider alternatives when assigning merit to publications.

\section{ACKNOWLEDGEMENTS}

This research was conducted as part of a working group 'The role of publication-related biases in ecology' - supported by the National Center for Ecological Analysis and Synthesis (NCEAS), funded by NSF (Grant no. DEB-0072909).

\section{REFERENCES}

[1] Kokko H, Sutherland WJ. What do impact factors tell us? Trends Ecol Evol 1999; 14: 382-384.

[2] Krell FT. Why impact factors don't work for taxonomy. Nature 2002; 415: 957. 
[3] Ball P. Index aims for fair rankings of scientists. Nature 2005; 436: 900.

[4] Monastersky R. The number that's devouring science. Chron High Educ 2005; 10: 1-13.

[5] Lortie CJ, Aarssen LW, Budden AE, Koricheva JK, Leimu R, Tregenza T. Publication bias and merit in ecology. Oikos 2007; 116: $1247-1253$

[6] Yasui U. The 'genetic benefits' of female multiple mating reconsidered. Trends Ecol Evol 1998; 13: 246-250.

[7] Garfield E. The history and meaning of the journal impact factor. J Am Med Assoc 2006; 295: 90-93.
[8]

Amin M, Mabe M. Impact factors: use and abuse. Perspectives in Publishing. Newsletter No. 1. Oxford: Elsevier Science; 2000.

[9] Donner A, Rosner B. On inferences concerning a common correlation coefficient. Appl Stat 1980; 29: 69-76.

[10] Leimu R, Koricheva J. Does scientific collaboration increase the impact of ecological articles? Bioscience 2005; 55: 438-443.

[11] Braun T, Glanzel W, Schubert A. A Hirsch-type index for journals. Scientometrics 2006; 69: 169-173.

Received: April 08, 2008

Revised: June 20, 2008

Accepted: July 08, 2008

(C) Aarssen et al.; Licensee Bentham Open.

This is an open access article distributed under the terms of the Creative Commons Attribution License (http://creativecommons.org/licenses/by/2.5/), which permits unrestrictive use, distribution, and reproduction in any medium, provided the original work is properly cited. 